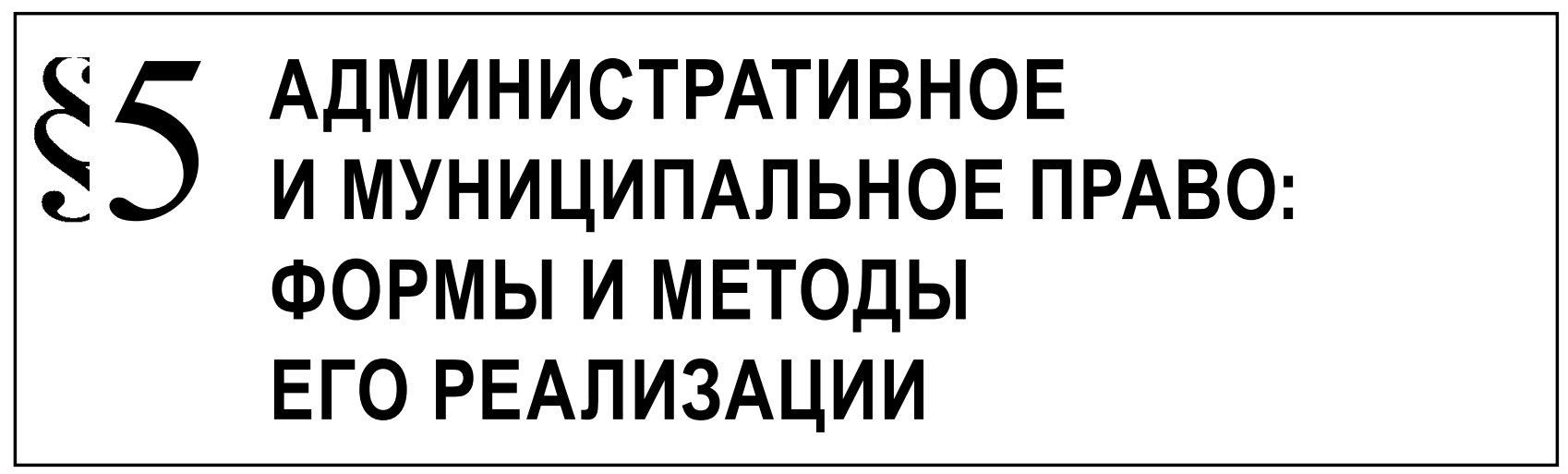

Софронова Д.А.

\title{
НЕКОТОРЫЕ ВОПРОСЫ СУДЕБНОЙ ЗАЩИТЫ НАРУШЕННЫХ ПРАВ И ЗАКОННЫХ ИНТЕРЕСОВ СУБЪЕКТОВ ПРЕДПРИНИМАТЕЛЬСТВА ПРИ ОСУЩЕСТВЛЕНИИ ГОСУДАРСТВЕННОГО КОНТРОЛЯ И НАДЗОРА
}

Аннотация. Предметом исследования в данной статье являются некоторые аспекты судебного механизма защиты прав юридических лиц и индивидуальных предпринимателей при осуществлении государственного контроля и надзора. Отмечается отсутствие единства базовых понятий в нескольких источниках права, регулирующих названные правоотношения. А именно, специальный закон о защите прав предпринимателей при осуществлении государственного контроля, процессуальное законодательство и официальная позиция Конституционного Суда Российской Федерации содержат противоречия в определении юридических средств и правовых последствий обжалования актов органов власти субъектами предпринимательства. Также автором анализируется институт признания недействительными результатов проверок как одно$2 о$ из способов защиты прав организаций и индивидуальных предпринимателей. При этом указывается на существенные недоработки правовой регламентации данного института. Из общей теории права и правоприменительной практики следует, что акт проверки как один из результатов проверочных мероприятий, вопреки содержанию закона о защите прав предпринимателей, не может быть оспорен по признакам его незаконности, поскольку не является правовым актом. Данная коллизия существенно сужает возможности предпринимателей для защиты своих законных интересов. Методологическую основу статьи составили такие общенаучные методы, как системный, сравнительный, статистический метод, метод анализа и синтеза. Новизна исследования заключается в том, что проводится исследование действующего законодательства в сфере судебной защиты прав предпринимателей с учетом Кодекса административного судопроизводства РФ и законопроекта "Об основах государственного и муниципального контроля (надзора) в Российской Федерации». В качестве вывода проведенного исследования автор заключает, что формальное закрепление различных механизмов защиты прав не обеспечивает должного уровня правовой защиты юридических лиц и индивидуальных предпринимателей, а существующая правовая неопределенность лишает эфрфективности специальное законодательство в области государственного контроля (надзора).

Ключевые слова: государственный контроль, государственный надзор, акт проверки, защита прав предпринимателей, судебная защита прав, оспаривание решений, недействительность правового акта, недействующий правовой акт, незаконность правового акта, нарушения процедуры проверки.

Abstract. The research subject is the range of aspects of the mechanism of judicial protection of rights of legal entities and self-employed persons in the context of state control and supervision. The author notes the absence of a uniform statutory framework in several sources of law regulating the mentioned legal relationship. Particularly, the special law on the protection of rights of self-employed persons in the context of state control, procedural legislation and the official position of the Constitutional Court of the Russian Federation contain contradictions in the definition of legal means and legal consequences of appeal of public authorities' decisions by business entities. The author analyzes the institution of invalidating the results of inspection as one of the ways of protection of rights of organizations and self-employed persons. The author points out the significant shortcomings of legal regulation of this institution. The general theory of law and law enforcement practice demonstrate that the inspection act, as one of the results of 
inspection, contrary to the content of the law on the protection of entrepreneurs' rights, can't be litigated according to the signs of its illegality, since it is not a legal act. This collision significantly narrows entrepreneurs' capacities to protect their legal interests. The research methodology is based on general scientific methods including the system, comparative and statistical methods, analysis and synthesis. The novelty of the research consists in the fact that the author studies the current legislation in the sphere of judicial protection of entrepreneurs' rights with regard to the Administrative Procedure Rules and the draft law "On the fundamentals of state and municipal control (supervision) in the Russian Federation". The author concludes that the formal consolidation of different mechanisms of protection of rights doesn't guarantee the due level of legal protection of legal entities and self-employed persons, and the existing legal ambiguity whittles the effectiveness of special legislation in the sphere of state control (supervision).

Key words: violations of the procedure of inspection, illegality of a statutory instrument, invalid statutory instrument, invalidity of a legal act, appeal of decisions, judicial protection of rights, protection of entrepreneurs' rights, act of inspection, state supervision, state control.

K орреляция деятельности властвующих субъектов и предпринимательских структур является основополагающим условием процветания государства с рыночной экономикой. Как верно отмечено Россинским Б. В., реализация надзорных полномочий органов исполнительной власти - один из действенных рычагов государственного регулирования деятельности хозяйствующих субъектов [1].

В связи с этим необходимость совершенствования института государственного управления в сфере предпринимательской деятельности можно справедливо признать одним из важнейших направлений современного российского государства.

Отношения в области организации и осуществления государственного контроля и надзора, защиты прав юридических лиц и индивидуальных предпринимателей при осуществлении данной государственной функции в настоящее время регулируются Федеральным законом от 26 декабря 2008 г. N 294-Ф3 «0 защите прав юридических лиц и индивидуальных предпринимателей при осуществлении государственного контроля (надзора) и муниципального контроля».

Анализ положений указанного закона позволяет выделить два пути защиты прав хозяйствующих субъектов при осуществлении публичными органами контрольно-надзорных мероприятий: судебный и внесудебный (административный) порядок защиты и обеспечения законных интересов организаций и индивидуальных предпринимателей при проведении проверочных мероприятий.

Федеральный закон о защите прав предпринимателей предусматривает несколько случаев обращения в суд за защитой нарушенных прав.

Пунктом 3 статьи 23 названного закона закреплено право на оспаривание действительности нормативно-правовых актов органов государственного контроля (надзора) или муниципальных правовых актов органов муниципального контроля, нарушающих права и (или) законные интересы юридических лиц, индивидуальных предпринимателей и не соответствующих законодательству Российской Федерации.
Право на оспаривание нормативно-правовых актов органов государственной власти может быть реализовано в порядке главы 21 Кодекса административного судопроизводства РФ (далее - КАС РФ) путем подачи искового заявления о признании нормативного правового акта недействующим, а также путем подачи в Суд по интеллектуальным правам заявления заинтересованного лица по правилам главы 23 Арбитражного процессуального кодекса РФ (далее - АПК РФ) с требованием о признании оспариваемого акта недействующим.

Как следует из изложенного, существует несоответствие базовых понятий (недействительность, отсутствие юридической силы), содержащихся в указанных законах.

Кроме того, в части 2 статьи 46 Конституции РФ выражено основополагающее правило: «решения и действия (или бездействие) органов государственной власти, органов местного самоуправления, общественных объединений и должностных лиц могут быть обжалованы в суд» [2].

Конкретизируя положения Конституции РФ, федеральный закон о контроле и надзоре в статье 21, пункте 2 статьи 23 закрепляет за юридическими лицами и индивидуальными предпринимателями право обжаловать действия (бездействия) органа государственного контроля (надзора), органа муниципального контроля, их должностных лиц, повлекшие за собой нарушение прав хозяйствующих субъектов.

При этом вопреки содержанию названных статьей действующее законодательство предусматривает возможность обжалования не только деяний, но и решений, а также ненормативных актов органов власти и их должностных лиц. Анализ процессуального законодательства позволяет выделить три способа судебного обжалования ненормативных правовых актов, решений, действий (бездействий) органов государственной власти.

Во-первых, это возможность обжалования постановления по делу об административном правонарушении, предусмотренная статьей 30.1 КоАП РФ, по результатам которого постановление ор- 


\section{Административное и муниципальное право 8 (104) 2016}

гана власти может быть отменено, изменено или оставлено без изменения.

Во-вторых, с 15 сентября 2015 года действует возможность оспаривания решения, действий (бездействий) органов и лиц, наделенных публичными полномочиями, в порядке административного судопроизводства путем подачи административного искового заявления. Этому посвящена глава 22 Кодекса административного судопроизводства РФ, которая заменила действовавший ранее Закон РФ от 27.04.1993 N 4866-1 (ред. от 09.02.2009) «Об обжаловании в суд действий и решений, нарушающих права и свободы граждан». Решением суда по данной категории дел оспариваемый акт может быть признан незаконным.

B-третьих, оспаривание ненормативных правовых актов, решений и действий (бездействий) государственных органов, затрагивающие права и законные интересы в сфере предпринимательской и иной экономической деятельности, предусмотрено главой 24 АПК РФ. Арбитражный суд, согласно АПК РФ, имеет полномочия на признание ненормативного правового акта недействительным, решений и действий (бездействий) незаконными.

Как видно, полномочия суда по результатам рассмотрения дел об оспаривании актов органов власти разнородны: акт может быть признан незаконным, недействующим или недействительным.

В целях установления гарантированности судебной защиты прав организаций и граждан при осуществлении в отношении них контрольно-надзорных мероприятий важно отметить следующее.

Как верно отмечено Зуевым О. М., «незаконность» включает в себя и «признание акта недействительным», и «признание акта недействующим» [3].

Под недействительностью нормативного акта в правовой науке понимается присутствие в нем неустранимых пороков, при наличии которых он не может иметь юридическую силу (принятие некомпетентным органом, с нарушением установленного порядка, в ненадлежащей форме, нарушение правил его опубликования) [4].

В соответствии с Постановлением Конституционного Суда РФ от 11 апреля 2000 года № 6-П, признание акта недействующим означает, что акт не подлежит применению с момента вступления решения суда в силу [5].

При этом Конституционный Суд РФ указывает на необходимость различать понятия: признание нормативного акта недействующим (не подлежащим применению) и признание нормативного акта недействительным (отмененным, не имеющим юридической силы).

Как следует из указанного Постановления, признание акта недействительным возможно лишь в порядке конституционного судопроизвод- ства в результате установления его несоответствия Конституции РФ. Признание акта недействующим возможно и судом общей юрисдикции.

Таким образом, существует некоторые противоречия закрепленных в законах положений официальной позиции Конституционного Суда РФ. В связи с этим представляется крайне важным привести действующее законодательство к единообразию и в соответствие с толкованием судебного органа конституционного контроля. Целесообразно исключить понятие «недействительность» правового акта в тех нормах права, в которых идет речь об оспаривании их соответствия федеральному закону в порядке гражданского (в том числе арбитражного) или административного судопроизводства.

Стоить отметить, что в настоящее время правовая база в данной сфере отношений претерпевает положительные изменения. Министерство экономического развития РФ подготовило проект Федерального закона «Об основах государственного и муниципального контроля (надзора) в Российской Федерации», который призван заменить ныне действующий закон и который более детально регулирует сферу отношений при осуществлении государственного и муниципального контроля (надзора). Однако в данном законопроекте сохранено положение о признании актов органов власти недействительными.

Подконтрольные субъекты довольно часто прибегают к судебному механизму защиты своих прав. Так, например, по данным Федеральной службы по экологическому, технологическому и атомному надзору, в 2014 году судами удовлетворено 443 заявления об обжаловании оснований проверок, предписаний об устранении нарушений, постановлений о привлечении к административной ответственности, вынесенных по итогам проверок, проведенных Ростехнадзором [6, с.50].

Одним из активно применяемых способов защиты прав подконтрольных субъектов выступает институт признания недействительными результатов проверок, предусмотренный статьей 20 федерального закона о защите прав предпринимателей. Так, например, в 2015 году из 189027 проверок, проведенных Министерством Российской Федерации по делам гражданской обороны, чрезвычайным ситуациям и ликвидации последствий стихийных бедствий в отношении юридических лиц и индивидуальных предпринимателей, результаты 36 из них были признаны недействительными $(0,019 \%)$, в том числе 19 - по решению суда [7]. По данным Федеральной службы по экологическому, технологическому и атомному надзору, в 2014 году было проведено 140586 проверок [6, c.45], результаты 11 из них были признаны недействительными $(0,007 \%)$ [8]. 
Однако данный механизм защиты нельзя назвать совершенным. Для целей его применения необходимо выяснить, что является результатом проверки.

Согласно статье 16 названного закона, по результатам проверки должностными лицами органа государственного контроля (надзора), органа муниципального контроля, проводящими проверку, составляется акт по установленной форме в двух экземплярах. В акте проверки, в частности, указываются сведения о результатах проверки, в том числе о выявленных нарушениях обязательных требований и требований, установленных муниципальными правовыми актами, об их характере и о лицах, допустивших указанные нарушения. К акту проверки в случае выявления нарушений прилагаются предписание об устранении выявленных нарушений.

Из толкования рассматриваемого закона следует, что акт проверки является итоговым документом проведения проверочных мероприятий в отношении юридических лиц и индивидуальных предпринимателей, то есть представляет собой результат проверки.

В силу статьи 20 федерального закона о контроле и надзоре, результаты проверки, проведенной с грубым нарушением установленных законом требований к организации и проведению проверок, не могут являться доказательствами нарушения юридическим лицом, индивидуальным предпринимателем обязательных требований и требований, установленных муниципальными правовыми актами, и подлежат отмене вышестоящим органом государственного контроля (надзора) или судом на основании заявления юридического лица, индивидуального предпринимателя.

Для отмены какого-либо акта необходимо установить его незаконность. Как следует из приведенных положений законодательства, в судебном порядке возможно обжаловать лишь правовые акты органов государственной власти - нормативные и ненормативные, а также их решения, действия (бездействия).

Однако акт проверки не обладает признаками правового акта, поскольку является процессуальным документом, фиксирующим процедуру и обстоятельства контрольно-надзорного мероприятия.

Судебно-арбитражная практика подтверждает данный вывод. Так, например, в постановлении арбитражного суда по делу об оспаривании коммерческой организацией предписания и актов проверки МВД России указано, акт проверки не содержит властно-распорядительных предписаний, распоряжений, влекущих для заявителя юридические последствия; не устанавливает и не изменяет обязанности и права заявителя; не создает обязанность нарушителя нести ответственность за совершен- ные правонарушения. Акт проверки лишь отражает установленные в ходе проверки обстоятельства, выявленное нарушение, установленное проверяющим в ходе проверки, а также содержит сделанные на основании анализа этих обстоятельств выводы проверяющего, то есть носит информационный характер. Каких-либо распоряжений, нарушающих права и интересы подконтрольного субъекта в сфере предпринимательской и иной экономической деятельности, в акте проверки не содержится [9].

Таким образом, поскольку акт проверки не является правовым актом, а обжалование процессуальных документов действующим процессуальным законодательством не предусмотрено, вопрос о незаконности, а тем более недействительности данного документа судом разрешен быть не может. В случае обжалования акта проверки в арбитражный суд или суд общей юрисдикции производство по делу должно быть прекращено [10].

Следовательно, акт проверки как таковой невозможно отменить путем признания в судебном порядке его незаконности.

Отменить в судебном порядке акт проверки, принятый по результатам проведения контрольно-надзорных мероприятий, возможно лишь в том случае, если он обладает признаками правового акта, то есть содержит определенные правила поведения. Например, если акт содержит требование по устранению выявленных недостатков и сроки для их устранения, то в данном случае акт в соответствующей части является ненормативным правовым актом, как вынесенный уполномоченным органом в отношении конкретного лица и носящий для этого лица обязательный характер [11].

Однако такой практический подход представляется не совсем верным. Исходя из буквального толкования статьи 16 федерального закона о государственном контроле, требование об устранении нарушений не может содержаться в самом акте проверки, поскольку акт выполняет лишь справочноинформационную функцию. Акт проверки по своей природе сходен с протоколом судебного заседания или осуществления отдельных процессуальных действий в гражданском, уголовном, арбитражном или административном процессе. Протокол, также как и акт проверки, отражает совершенные действия и принятые решения, то есть фиксирует ход осуществления процедуры, но сам не является распорядительным документом. Поэтому в акте проверки может быть ссылка на решение проверяющего органа, но само решение должно быть выражено в отдельно принятом документе, который может быть оспорен по правилам главы 24 АПК РФ и главы 22 КАС РФ.

Следовательно, акт проверки как документ, фиксирующий процедуру проведения проверки, не может быть отменен на том основании, что имеют- 


\section{Административное и муниципальное право 8 (104) • 2016}

ся грубые нарушения установленных законом требований к организации и проведению проверок.

Кроме того, как указано в анализируемом законе, требование об устранении выявленных в ходе проверки нарушений должно содержаться в прилагаемом к акту проверки предписании, которое содержит властно-распорядительные указания, возлагает юридические обязанности, и соответственно, может быть оспорено в судебном порядке.

Таким образом, анализ положений законодательства позволяет прийти к выводу о том, что статью 20 федерального закона о защите прав предпринимателей следует толковать ограничительно: не всякий результат проверки можно спорить по признакам его недействительности. Оспорить можно предписание контролирующего органа об устранении выявленных нарушений, решение проверяющего органа, но не акт проверки.

Такие коллизии, возникающие в процессе осуществления контрольно-надзорных мероприятий, лишают хозяйствующих субъектов должного уровня правовой защиты их прав и законных интересов при осуществлении государственного, муниципального контроля (надзора). Сказанное вызывает к жизни необходимость внесения коррективов в законодательные положения относительно института оспаривания результатов проверок хозяйствующих субъектов при осуществлении в отношении них контрольно-надзорных мероприятий.

Четкое и недвусмысленное правовое регулирование есть показатель качества правовой системы государства, необходимое условие прозрачного и отлаженного функционирования государственных органов, бесконфликтного взаимодействия контролирующих и подконтрольных субъектов.

Зырянов С. М. справедливо отмечает, что «административно-надзорное производство как самостоятельная часть административного процесса является необходимой гарантией прав и законных интересов граждан и организаций - участников административно-надзорных правоотношений» [12].

Таким образом, существование в законодательстве непреодолимых без качественной правотворческой деятельности пробелов приводит к отсутствию гарантированности защиты прав и интересов субъектов предпринимательства при осуществлении в отношении них государственного контроля и надзора.

\section{Библиография:}

1. Административное право: учебник / Б. В. Россинский, Ю. Н. Старилов. - 4-е изд., пересмотр. и доп. - М.: Норма. 2009, с. 529;

2. Конституция Российской Федерации (принята всенародным голосованием 12.12.1993) // «Собрание законодательства РФ», 04.08.2014, N 31, ст. 4398;

3. Зуев О. М. Незаконные нормативно-правовые акты в Российской правовой системе: Автореферат диссертации на соискание ученой степени кандидата юридических наук. Специальность 12.00.01-Казань, 2007.-28 с.;

4. Ельцова Т. С. Действие во времени нормативных правовых актов и актов официального нормативного толкования: проблемы теории и практики: автореферат дис. ... кандидата юридических наук: 12.00.01.-Нижний Новгород, 2010. - 22 с.;

5. Постановление Конституционного Суда РФ от 11 апреля 2000 г. N 6-П «По делу о проверке конституционности отдельных положений пункта 2 статьи 1, пункта 1 статьи 21 и пункта 3 статьи 22 Федерального закона «0 прокуратуре Российской Федерации» в связи с запросом Судебной коллегии по гражданским делам Верховного Суда Российской Федерации» // «Вестник Конституционного Суда Российской Федерации», 2000 г., N 4;

6. Доклад Ростехнадзора об осуществлении государственного контроля (надзора) в 2014 году и об эффективности такого контроля (надзора) [66 с.] // Официальный сайт Федеральной службы по экологическому, техническому и атомному надзору РФ. URL: http://www.gosnadzor.ru (дата обращения: 26.12.2015);

7. Осуществление государственного контроля (надзора) и муниципального контроля за 2015 год // Официальный сайт МЧС России. URL: http://www.mchs.gov.ru/activities/stats/Statistika_ob_osushhestvlenii_gosudarstv/2015_god;

\section{References (transliterated):}

1. Administrativnoe pravo: uchebnik / B. V. Rossinskii, Yu. N. Starilov. - 4-e izd., peresmotr. i dop. - M.: Norma. 2009, s. 529;

2. Konstitutsiya Rossiiskoi Federatsii (prinyata vsenarodnym golosovaniem 12.12.1993) // «Sobranie zakonodatel'stva RF», 04.08.2014, N 31, st. 4398;

3. Zuev O. M. Nezakonnye normativno-pravovye akty v Rossiiskoi pravovoi sisteme: Avtoreferat dissertatsii na soiskanie uchenoi stepeni kandidata yuridicheskikh nauk. Spetsial'nost' 12.00.01-Kazan', 2007.-28 s.;

4. El'tsova T. S. Deistvie vo vremeni normativnykh pravovykh aktov i aktov ofitsial'nogo normativnogo tolkovaniya: problemy teorii i praktiki: avtoreferat dis. ... kandidata yuridicheskikh nauk: 12.00.01.-Nizhnii Novgorod, 2010. - 22 s.;

5. Postanovlenie Konstitutsionnogo Suda RF ot 11 aprelya 2000 g. N 6-P «Po delu o proverke konstitutsionnosti otdel'nykh polozhenii punkta 2 stat'i 1, punkta 1 stat'i 21 i punkta 3 stat'i 22 Federal'nogo zakona «0 prokurature Rossiiskoi Federatsii» v svyazi s zaprosom Sudebnoi kollegii po grazhdanskim delam Verkhovnogo Suda Rossiiskoi Federatsii» // «Vestnik Konstitutsionnogo Suda Rossiiskoi Federatsii», 2000 g., N 4;

6. Doklad Rostekhnadzora ob osushchestvlenii gosudarstvennogo kontrolya (nadzora) v 2014 godu i ob effektivnosti takogo kontrolya (nadzora) [66 c.] // Ofitsial'nyi sait Federal'noi sluzhby po ekologicheskomu, tekhnicheskomu i atomnomu nadzoru RF. URL: http://www.gosnadzor.ru (data obrashcheniya: 26.12.2015);

7. Osushchestvlenie gosudarstvennogo kontrolya (nadzora) i munitsipal'nogo kontrolya za 2015 god // Ofitsial'nyi sait MChS Rossii. URL: http://www.mchs.gov.ru/activities/stats/Statistika_ob_osushhestvlenii_gosudarstv/2015_god; 